\title{
Correlation between Serum Calcium and Phosphate with Coronary Artery Calcium Scores on Cardiac MSCT Examination
}

\author{
Rosita $^{1}$, Sri Asriyani ${ }^{1}$, Bachtiar Murtala ${ }^{1}$, Andi Alfian Zainuddin², Muzakkir Amir ${ }^{3}$, \\ Muhammad Ilyas ${ }^{1}$ \\ ${ }^{1}$ Department of Radiology Department, Faculty of Medicine, University of \\ Hasanuddin, Makassar \\ ${ }_{2}^{2}$ Public Health and Family Medicine Department, Faculty of Medicine, University \\ of Hasanuddin, Makassar \\ 3Department of Cardiology and Vascular Medicine, Faculty of Medicine, \\ University of Hasanuddin, Makassar \\ Email : rositakaidr@gmail.com \\ Receive : Oct 10 $0^{\text {th }}$ 2019. Revised : Oct 20th2019. Published: Dec $20^{\text {th }} 2019$ \\ DOI : https://doi.org/10.22219/sm.Vol15.SMUMM2.9970
}

\begin{abstract}
Increased serum calcium and phosphate associated with cardiovascular disease in patients with chronic kidney disease, but research on the relationship between coronary artery calcium scores with serum calcium and phosphate in individuals with normal kidney function is lacking. We explore the relationship of serum calcium and phosphate levels with coronary atherosclerosis as assessed by cardiac Multislice Computed Tomography (MSCT) in individuals with normal kidney function. This study aims to assess the correlation of calcium level scores on cardiac MSCT examination with serum calcium and phosphate levels, and assess the association with risk factors for coronary heart disease. This study was a cross-sectional study of 40 subjects who underwent cardiac MSCT examination with normal kidney function, at RSUP Dr. Wahidin Sudirohusodo Makassar during the March-July 2019 period. The results showed an correlation between coronary artery calcium scores with calcium and serum phosphate (serum calcium $r=0.67$, serum phosphate $\mathrm{r}=0.53, \mathrm{p}<0.05)$.
\end{abstract}

Keywords : MSCT, coronary artery, coronary artery calcium scores, serum calcium, serum phosphate.

Copyright $(2019$, First Author et al This is an open access article under the CC-BY-SA license

\section{INTRODUCTION}

Serum calcium and phosphorus play an essential physiological role in bone mineralization, energy production, membrane transport, signal transduction, and vascular function (Taylor et al., 2009). Recent experimental and epidemiological studies reported that higher serum calcium or phosphorus level could be associated with the pathogenesis of cardiovascular disease (CVD), including atherosclerosis (Foley et al.,2009). Cardiovascular disease is the most common cause of death in patients with chronic kidney disease (CKD) and vascular calcification is one of the strongest predictors of cardiovascular risk (Palit and Kendrick, 2014). 
Experimental and clinical studies show that disorders in mineral metabolism including calcium and phosphate homeostasis can initiate and promote vascular calcification in patients with CKD (Palit and Kendrick, 2014). Serum phosphate has emerged as a major regulator of vascular calcification in patients with CKD. Increased serum phosphate levels, even in the normal laboratory range, have been linked to calcification and stiffness of blood vessels in patients with and without CKD (Adeney et al., 2009; Kendrick and Chonchol, 2011). Two very large studies (total patient population $>30,000)$ from Korea also showing that coronary artery calcification is directly related to circulating calcium levels (Shin et al., 2012; Kwak et al., 2014).

Coronary artery calcium scores (CACS) are non-invasive examinations of coronary arteries in which the amount of calcium in the coronary arteries is determined using cardiac computed tomography (Greenland et al, 2018; Blankstein et al, 2017). CAC scores play an important role in the stratification of cardiovascular risk. Several studies have shown that CAC scores are significantly associated with the occurrence of major cardiovascular events and in the medium and long-term follow-up (Neves et al., 2017). The CAC score itself is a reliable independent predictor for CHD (Osawa K et al., 2016). Currently, guidelines from around the world support the measurement of CAC to improve the prediction of clinical risk in asymptomatic individuals (Greenland et al., 20107; Hecht et al., 2017). The main system for the quantification of CAC scores is the Agatston method (Agatston et al., 1990). The Agatston method is used as a reference for most population databases and publications that involve risk stratification and is the method most often used in clinical practice (Blaha et al., 2017).

Therefore, we explored the relationship between serum calcium and phosphate levels with coronary atherosclerosis assessed by cardiac multislice computed tomography (MSCT), a method useful in predicting cardiovascular disease in participants with normal kidney function. Next, we also looked at how it relates to various risk factors for coronary heart disease.

\section{METHODS}

This cross sectional study consisted of 40 consecutive participants who underwent cardiac MSCT evaluation using 64 multislice computed tomography (MSCT) from Maret 2019 to Juli 2019 at RSUP Dr. Wahidin Sudirohusodo Makassar. Participants were excluded if any one of the following criteria was met: age $<18$ years, modification of diet in renal disease (MDRD) glomerular filtration rate (GFR) under $60 \mathrm{~mL} / \mathrm{min} / 1.73 \mathrm{~m}^{2}$, or insufficient medical records. Written informed consent was received from all patients. This study has received ethical approval from the Health Research Ethics Committee of the Faculty of Medicine, Hasanuddin University, Makassar, number: 462/UN4.6.44.5.31/PP36/2019.

Medical history of hypertension, diabetes mellitus, dyslipidemia and smoking status were systematically acquired. Height, body weight and blood pressure were measured during visits. 
Serum calcium and phosphate level were measured after a minimum of 12 hour fasting period on the day of CT scan as the part of the clinical work-up. Patients with initial heart rate higher than 60 beats/min before MSCT examination received betablocker 1-2 hours before CT examination. Patients were scanned using a 64-slice CT scanner (Hight Speed VCT GE, a nonenhanced prospective electrocardiogram (ECG)-gated scan was performed to measure Coronary Artery Calcium Scores (CACS). Coronary CT were evaluated by residents and confirmed by an experienced radiologist.

All data obtained are recorded in the research form, then grouped according to the purpose and type of data, then the data will be processed according to the Spearman and Mann Whitney statistical methods. All analyses were performed using the Statistical Package for the Social Sciences (SPSS, version 22; SPSS, Chicago, IL, USA).

\section{RESULTS AND DISCUSSION}

Baseline characteristics of the study population

Baseline clinical characteristics and laboratory data for the study population are illustrated in Table 1. In 40 subjects enrolled in the present study, 23 (57\%) were male subjects, and the age range was 51-60 years (45\%). Dyslipidemia, DM and hypertension was present in 85\%, 55\%, and $57.5 \%$ of the patients, respectively. The medians and interquartile ranges of serum $\mathrm{Ca}, \mathrm{P}$ and $\mathrm{CAC}$ were $9.00(8.00-11.40) \mathrm{mg} / \mathrm{dL}, 3.35(3.00-5.00) \mathrm{mg} / \mathrm{dL}$, and $62(0-792)$

Table 1. Characteristics of the study population

\begin{tabular}{lccc}
\hline & Group & $\mathrm{n}$ & $\%$ \\
\hline Sex & Male & 23 & 57 \\
& Female & 17 & 42.5 \\
\hline Age & $31-40$ & 1 & 2.5 \\
(Years) & $41-50$ & 8 & 20 \\
& $51-60$ & 18 & 45 \\
& $61-70$ & 11 & 27 \\
& $71-80$ & 1 & 2.5 \\
& $81-90$ & 1 & 2.5 \\
\hline Smoking & Yes & 20 & 50 \\
& No & 20 & 50 \\
\hline Obesity & Yes & 9 & 22.5 \\
& No & 31 & 77.5 \\
\hline Dyslipidemia & Yes & 34 & 85 \\
& No & 6 & 15 \\
\hline Hypertension & Yes & 23 & 57.5 \\
& No & 17 & 42.5 \\
\hline DM & Yes & 22 & 55 \\
& No & 18 & 45 \\
\hline
\end{tabular}




\begin{tabular}{lc}
\hline $\begin{array}{l}\text { Serum Ca } \\
(\mathrm{mg} / \mathrm{dl})\end{array}$ & $9.00(8.00-11.40)$ \\
\hline $\begin{array}{l}\text { Serum } \mathrm{P} \\
(\mathrm{mg} / \mathrm{dl})\end{array}$ & $3.35(3.00-5.00)$ \\
\hline $\begin{array}{l}\mathrm{CACS} \\
\text { (agatston) }\end{array}$ & $62(0-792)$ \\
\hline Ca $=$ calcium $;=$ P & \\
\hline
\end{tabular}

$\mathrm{Ca}=$ calcium; $\mathrm{P}=$ phosphate; $\%=$ persentage;

$\mathrm{CACS}=$ coronary artery calcium score

Association between serum calcium, phosphate and CACSwith risk. factors for coronary heart disease (CHD)

The table 2 shows the relationship between serum calcium and phosphate and total calcium score with risk factors for coronary heart disease including sex, dyslipidemia, hypertension, smoking, diabetes, and obesity. The results of statistical tests obtained serum calcium and phosphate levels and CACS in samples with dyslipidemia, hypertension, and diabetes have p-value $<0.05$ which means there is a significant difference between serum calcium and phosphate levels and CAC in samples with dyslipidemia, hypertension and diabetes compared to those no.

Serum calcium is directly related to circulating lipids, glucose metabolism, body mass index (BMI), and blood pressure (Reid et al., 2015). The prevalence and development of CAC are also associated with traditional risk factors for atherosclerosis such as old age, male sex, hypertension, dyslipidemia, diabetes, smoking status, family history of premature CHD (Osawa K et al., 2016). The study of Gassett et al found a strong association between risk factors that cause cardiovascular disease (CVD) and the development of CAC over 10 years in large multi-ethnic populations (Gassett et al., 2015). These risk factors can be intermediaries in the causal chain or they can be independent associations that are not directly involved in the calcium and vascular relationship (Reid et al., 2017).

Table 2. Association between serum calcium, phosphate and CACSwith risk factors for CHD

\begin{tabular}{|c|c|c|c|c|c|c|c|}
\hline & & Serum Calcium & $\mathrm{mg} / \mathrm{dl})$ & Serum Phospha & mgdl) & CACS & \\
\hline & $\mathrm{n}$ & Med(Min-Max) & $\begin{array}{c}\mathrm{p} \\
\text { value* }\end{array}$ & Med(Min-Max) & $\begin{array}{c}\mathrm{p} \\
\text { value* }\end{array}$ & Med(Min-Max) & $\begin{array}{c}\mathrm{p} \\
\text { value } \\
*\end{array}$ \\
\hline Dyslipidemia & & & 0.002 & & 0.023 & & $\begin{array}{c}0.00 \\
2\end{array}$ \\
\hline Yes & 34 & $9.15(8.30-11.40)$ & & $3.40(2.70-5.00)$ & & $94(0-792)$ & \\
\hline No & 6 & $8.40(8.00-9.00)$ & & $2.55(2.50-4.00)$ & & $0(0-0)$ & \\
\hline Hypertension & & & 0.014 & & 0.001 & & $\begin{array}{c}0.00 \\
1\end{array}$ \\
\hline $\begin{array}{l}\text { Yes } \\
\text { No }\end{array}$ & $\begin{array}{l}23 \\
17\end{array}$ & $\begin{array}{l}9.30(8.30-11.40) \\
8.70(8.00-10.20)\end{array}$ & & $\begin{array}{l}3.70(2.50-5.00) \\
2.80(2.50-4.00)\end{array}$ & & $\begin{array}{c}201(0-792) \\
0(0-245)\end{array}$ & \\
\hline $\mathrm{DM}$ & & & 0.017 & & 0.019 & & $\begin{array}{c}0.00 \\
3\end{array}$ \\
\hline $\begin{array}{l}\text { Yes } \\
\text { No }\end{array}$ & $\begin{array}{l}22 \\
18\end{array}$ & $\begin{array}{c}9.30(8.30-11.40) \\
8.70(8.00-10.4)\end{array}$ & & $\begin{array}{l}3.45(2.70-5.00) \\
3.10(2.50-4.30)\end{array}$ & & $\begin{array}{c}123(0-792) \\
0(0-431)\end{array}$ & \\
\hline Obesity & & & 0.987 & & 0.783 & & $\begin{array}{c}0.22 \\
0\end{array}$ \\
\hline Yes & 9 & $9.10(8.50-10.40)$ & & $3.40(2.50-4.00)$ & & $18(0-338)$ & \\
\hline No & 31 & $9.00(8.00-11.40)$ & & $3.20(2.50-5.00)$ & & $90(0-792)$ & \\
\hline
\end{tabular}




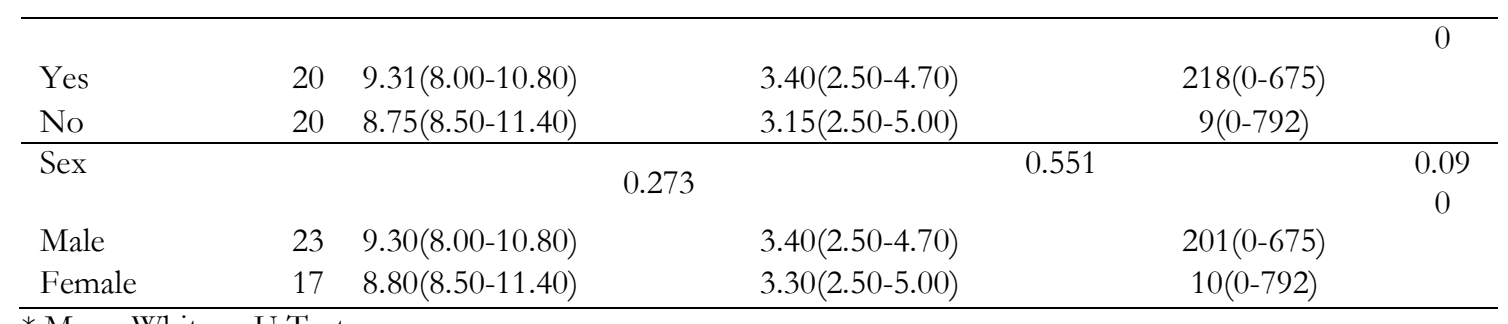

* Mann Whitney U Test

Table 3 with the results of the Spearman correlation test showed that there was a significant correlation between age and CAC score with $\mathrm{p}$-value $<0.05$ and $\mathrm{r}$-value of 0.34 . The older you get, the higher the CAC score. But this correlation has a weak correlation strength with an r-value of 0.34 . This shows that atherosclerosis can also occur at a young age, and this can be influenced by several risk factors such as dyslipidemia, hypertension, diabetes, obesity and other risk factors experienced at a young age. (Hong, 2010) In the CARDIA study of young adults, CACS was obtained in those aged 32-46 years and many of them had CACS $>0$ especially those who had one or more risk factors (Greenland et al., 2018).

Tabel 3. Correlation serum calcium, phosphate and CACS with age

\begin{tabular}{cccc}
\hline & \multicolumn{3}{c}{ Age } \\
\cline { 2 - 4 } & $\mathrm{n}$ & $\mathrm{p}$ & $\mathrm{r}$ \\
\hline Serum Ca & 40 & 0.791 & 0.043 \\
Serum P & 40 & 0.518 & 0.105 \\
CACS & 40 & 0.030 & 0.344 \\
\hline
\end{tabular}

$\mathrm{Ca}=$ calcium; $\mathrm{P}=$ phosphate; $\mathrm{CACS}=$ coronary artery calcium scores Spearman test

\section{Correlation between serum calcium and phosphate level with CACS}

The next table shows the relationship between serum calcium and phosphate levels with total calcium scores in the study sample. Spearman's test showed a significant correlation between serum calcium levels with total calcium scores with the strength of a strong positive relationship as evidenced by the value of $r=0.67$, as well as serum phosphate levels with total calcium scores with a strength of a moderate positive relationship as evidenced by the value of $r=0.53$.

The relationship between calcium and phosphate was first studied in patients with kidney failure. It is known that mineral regulation is disrupted in patients with impaired kidney function, resulting in calcium and phosphate deposits that cause calcification of blood vessels and increased cardiovascular disease. (Reid et al., 2016) However, evidence of serum and phosphate levels affecting cardiovascular events in patients with normal kidney function is lacking. Shin et al (2012) found that serum calcium and phosphate were independently associated with the presence of calcified plaque in individuals with normal kidney function.

A study by McGovern et al in a large community-based population found that serum phosphate levels were associated with cardiovascular events and mortality in people with normal kidney function and those suffering from CKD. (McGovern et al., 2013) The study of Park et al. 
stated that increased phosphate concentrations even within the normal range were significantly associated with CAC subjects without renal dysfunction (Park et al., 2016).

Table 4. Correlation between serum calcium and phosphate with CACS

\begin{tabular}{cccc}
\hline & \multicolumn{3}{c}{ CACS } \\
\cline { 2 - 4 } & $\mathrm{n}$ & $\mathrm{p}$ & $\mathrm{r}$ \\
\hline Serum Ca & 40 & $<0.0001$ & 0.67 \\
Serum P & 40 & $<0.0001$ & 0.53 \\
\hline
\end{tabular}

$\mathrm{Ca}:$ calcium; P : phosphate; CACS $=$ coronary artery calcium scores; Spearman test.

\section{CONCLUSION}

Elevated serum levels of calsium and phosphate are significantly associated with the presence of calcified coronary atherosclerotic plaquein subjects with normal kidney function

\section{REFERENCES}

Agatston, A.S., Janowitz, W.R., Hildner, F.J. et al.(1990). Quantification of coronary artery calcium using ultrafast computed tomography. J Am Coll Cardiol 15:827-832.

Blankstein, R. Gupta, A., Rana, J.S.et al.(2017). The Implication of Coronary Artery Calcium Testing for Cardiovascular Disease Prevention and Diabetes. EndocrinolMetabolism. 32, $47-57$.

Blaha, M.J., Mortensen, M.B., Kianoush, S. et al.(2017). Coronary Artery Calcium Scoring: Is It Time for a Change in Methodology?, JACC: Cardiovascular Imaging, 10(8), pp. 923-937. doi: 10.1016/j.jcmg.2017.05.007.

Foley, R.N., Collins, A.J., Herzog, C.A., et al.(2009). Serum phosphorus levels associate with coronary atherosclerosis in young adults. J Am Soc Nephrol.20:397-404

Gassett, A.J., Sheppard, L., McClelland, R.L., Olives, C.,et al.(2015). Risk Factors for Long-Term Coronary Artery Calcium Progression in the Multi-Ethnic Study of Atherosclerosis. Journal of the American Heart Association, 4(8), p. e001726. doi: 10.1161/JAHA.114.001726.

Greenland, P., Alpert, J.S., Beller, G.A., et al. (2010). ACCF/AHA guideline for assessment of cardiovascular risk in asymptomatic adults: a report of the American College of Cardiology Foundation/American Heart Association Task Force on Practice Guidelines developed in collaboration with the American Society of Echocardiography, American Society of Nuclear Cardiology, Society of Atherosclerosis Imaging and Prevention, Society for Cardiovascular Angiography and Interventions, Society of Cardiovascular Computed Tomography, and Society for Cardiovascular Magnetic Resonance. J Am Coll Cardiol 56:e50-e103

Greenland, P., Blaha, M., Budo $\square$, M.et al.(2018). Coronary Calcium Score and Cardiovascular Risk. J. Am. Coll. Cardiol. 72, 434-447.

Hecht, H., Blaha, M.J., Berman, D.S., etal. (2017). Clinical indications for coronary artery calcium scoring in asymptomatic patients: expert consensus statement from the Society of 
Cardiovascular Computed Tomography. Journal Cardiovascular Computed Tomography 11:157-168.

Hong, Y.M. (2010). Atherosclerotic cardiovascular disease beginning in childhood, Korean Circulation Journal, 40(1), pp. 1-9. doi: 10.4070/kcj.2010.40.1.1.

Kendrick, J. and Chonchol, M.M. (2011). The Role of Phosphorus in the Development and Progression of Vascular Calcification. NIH Public Access, 5(58), pp. 826-834. doi:10.1053/j.ajkd.2011.07.020. NIH.

Kwak, S.M., Kim, J.S., Choi, Y., et al. (2014). Dietary intake of calcium and phosphorus and serum concentration in relation to the risk of coronary artery calcification in asymptomatic adults. Arterioscler Thromb Vasc Biol. ;34:1763-1769.

McGovern, A.P., Lusignan, S., Vlymen, J., et al.(2013). Serum Phosphate as a Risk Factor for Cardiovascular Events in People with and without Chronic Kidney Disease: A Large Community Based Cohort Study.PLoS ONE, 8(9). doi: 10.1371/journal.pone.0074996.

Neves, P. O., Andrade, J. and Monção, H. (2017). Coronary artery calcium score: current status. Radiologia Brasileira, 50(3), pp. 182-189. doi: 10.1590/0100-3984.2015.0235.

Osawa, K., Nakanishi, R. and Budoff, M.M. (2016). Coronary Artery Calcification; report from the Multi-Ethnic Study of Atherosclerosis. HHS Public Access, 3(11), pp. 287-293. doi: doi:10.1016/j.gheart.2016.08.001.

Palit, S. and Kendrick, J. (2014) . Vascular Calcification in Chronic Kidney Disease: Role of Disordered Mineral Metabolism. Current Pharmaceutical Design, 20(37), pp. 5829-5833. doi: 10.2174/1381612820666140212194926.

Park, K.S., Park, J., Choi, S.H.,et al.(2016). Serum phosphorus concentration and coronary artery calcification in subjects without renal dysfunction.Plos one journal, 11(3), pp. 1-11. doi: 10.1371/journal.pone.0151007

Reid, I.R., Gamble, G.D., and Bolland, M.J. (2016). Circulating calcium concentrations, vascular disease and mortality: a systematic review. Journal Intern Med. 279:524-540.

Reid, I. R., Bristow, S. M. and Bolland, M. J. (2017) 'Calcium and cardiovascular disease', Endocrinology and Metabolism, 32(3), pp. 339-349. doi: 10.3803/EnM.2017.32.3.339.

Shin, S., Kim, K.J., Chang, H.J., et al. (2012). Impact of serum calcium and phosphate on coronary atherosclerosis detected by cardiac computed tomography. Eur Heart Journal . 33:28732881.

Taylor, J.G. and Bushinsky, D.A. (2009). Calcium and phosphorus homeostasis. Blood purification. $27: 387-394$ 